\title{
Pre-analytical Errors in the HIV Anti Retro Viral Therapy (ART) Lab- oratory of Teaching Referral Hospitals in Addis Ababa, Ethiopia
}

\section{Abay Sisay Misganaw*, Mulugeta Worku, Chala Bashea, Mamaru Nigus, Yisak Yoseph, and Habtamu Molla}

Department of Medical Laboratory Sciences, College of Health Sciences, Addis Ababa University, Addis Ababa, Ethiopia

*Corresponding author: Abay Sisay Misganaw, Department of Medical Laboratory Sciences, College of Health Sciences, Addis Ababa University, Addis Ababa, Ethiopia

\begin{abstract}
Aim: To assess the magnitude and associated factor of pre-analytical error in the Human Immunodeficiency Virus (HIV) antiretroviral therapy (ART) laboratory of a teaching referral hospitals in Addis Ababa, Ethiopia.

Methods: A cross-sectional descriptive study design was used from May 1, 2018 to Jun 30, 2018 by using both quantitative and quantitative data collection approach. Data was entered, cleaned using Statistical Package for the Social Science (SPSS) version 21 for Microsoft Windows.

Result: Among the 427 specimens submitted for laboratory testing, 41 (9.6\%) were not accepted for requested laboratory diagnosis, because of pre-analytical errors. The most frequent reasons were mislabeling followed by hemolyzed and clotted sample. $47.6 \%$ of the phlebotomist did not take phlebotomy related professional development training and errors were higher in those service offered by non-trained phlebotomist.

Conclusion: The overall pre-analytical error rate was considerably high, $9.6 \%$, even though, least magnitude compare to similar study. This finding suggests that strong comprehensive quality assurance interventions should be implemented in the health laboratory facilities in order to deliver quality laboratory result within the agreed turnaround time.
\end{abstract}

\section{Keywords}

Error, Laboratory, Pre analytic, Ethiopia

\section{List of Abbreviation/Acronyms}

ART: Anti Retro Viral Therapy; CLSI: Clinical and Laboratory Standards Institute; DRERC: Departmental Research and Ethics Review Committee; SOP: Standard Operating Procedure; SPSS: Statistical Package for the Social Science; TTP: Total Testing Process; WHO: World Health Organization

\section{Core Tip}

Quality assured laboratory is an essential part of the medical decision-making process. The finding shows the overall pre-analytical study rate was $9.6 \%$ and the most frequent reason for error was labeling error followed by hemolyzed and clotted sample and also, awareness of laboratory personnel about phlebotomy service that all laboratory personnel were not getting related competency-based training and even those who had training did not well practicing phlebotomy effectively.

\section{Background}

Laboratory services are the most important of the modern health care sector, $80 \%$ of all diagnosis is made on the basis of laboratory tests [1]. In spite of rapid advances in laboratory science, it is still susceptible to various manual and systemic errors [2].

A laboratory error is any defect from ordering tests to reporting results and appropriately interpreting and reacting on these. Process analysis has demonstrated that laboratory errors occur primarily in the pre analytic phase, influencing patient outcomes and expenses [3-5].

It is directly leading to increased healthcare costs and to trim down patient satisfaction. The number of errors typically depends on the management of samples, such as test requisition, specimen collection, storage and transportation, and specimen labeling are completed manually are managed out of the clinical laboratory $[6,7]$.

Citation: Misganaw AS, Worku M, Bashea C, Nigus M, Yoseph Y, et al. (2019) Pre Analytical Errors in the HIV Anti Retro Viral Therapy (ART) Laboratory of Teaching Referral Hospitals in Addis Ababa, Ethiopia. Int J Virol AIDS 6:057. doi.org/10.23937/2469-567X/1510057

Accepted: October 16, 2019: Published: October 18, 2019

Copyright: (c) 2019 Misganaw AS, et al. This is an open-access article distributed under the terms of the Creative Commons Attribution License, which permits unrestricted use, distribution, and reproduction in any medium, provided the original author and source are credited. 
Recent studies suggest that pre-analytical errors where the majority of laboratory errors occur, ranging from $31.6 \%$ to $75 \%$. It is the most complex process of the total testing process (TTP) and its effect has been frequently appearing in the analytical and the post-analytical stage [8-10].

Professionals who are performing phlebotomy services called phlebotomists and those who are undertaking phlebotomy need to be trained in procedures specific to the types of service they will perform as a continual professional development. Competency based training should include venous blood draws and procedures that make certain adequacy of collected specimen, reducing the risk of contamination, avoiding clerical error, avoiding infection and injury and time of transporting samples after collection [1113].

Efficient laboratory service is the join up of precision, accuracy, and speed of reports delivered to the patient. In spite of rapid advances in laboratory science, it is still susceptible to various manual and systemic errors. Over and above reducing the cost of medical errors, saving lives is the focal point for health care delivery. Saving even one life will make a positive social impact on both the patient and health care providers [14-16].

Likewise, in order to have clear view of shortcomings, knowledge gaps on the pre-analytical error in the ART laboratory and related factors which influence its quality in Ethiopia have not been documented, as far as our knowledge goes. Therefore, this study was carried out to assess magnitude and factors affecting the pre-analytical error in ART laboratory of Tikur anbessa specialized and St. Paul millennium Medical College, Addis Ababa, Ethiopia. This study also identified opportunities for laboratory personnel to reduce errors; improve patient safety and decrease operational costs.

\section{Methods}

\section{Study design and setting}

Cross-sectional descriptive study design was applied to determine the magnitude and factor affecting of pre-analytical errors in ART laboratory (consists of Hematology, Clinical Chemistry, CD4 and Viral load) at Tikur anbessa specialized and St. Paul millennium Medical College, Addis Ababa, Ethiopia from May 1 to Jun 30, 2018. Addis Ababa is the largest city in Ethiopia. It has 46 hospitals, among these 11 are public hospitals, of which 6 are under Addis Ababa Regional Health Bureau (AARHB) and 5 are specialized referrals (two teaching referral tertiary hospitals and under the Federal Ministry of Health), three uniform service (one army, one prison and one police hospitals), 4 are NGO's and the rest 28 are private hospitals [17].
This study focused on ART laboratories of two teaching referral hospitals in Addis Ababa, Ethiopia. These are Tikur Anbessa Specialized teaching hospital which is the largest tertiary specialized referral hospital in Ethiopia. In 1998, Tikuranbesa hospital which is also the largest teaching referral hospital in the country was given to Addis Ababa University (AAU) by the ministry of health $(\mathrm{MOH})$ for the faculty as a main teaching hospital. The hospital provides a tertiary level referral treatment and is open 24 hours for emergency services. The hospital offers diagnosis and treatment for approximately 370,000 400,000 patients a year. The hospital has 800 beds, with 130 specialists, 50 non-teaching doctors [18]. St. Paul's Hospital Millennium Medical College, it is teaching and referral hospital located western part of Addis Ababa. The hospital is built by Emperor Haile Selassie in 1969 with the help of the German Evangelical church aimed to serve the poor. A Millennium medical college was started in 2007 . Now it provides service as referral hospital for those people in Addis Ababa and referred from other places and teaching center for Medicine. The Hospital serves an average of 700 Patients daily including private wing. The Hospital has 340 beds. Both laboratories are at 4-star level SLIPTA laboratory quality management system, relatively superb eminence status [19].

\section{Sample size and Sampling technique}

All samples submitted to Tikur Anbessa and St. Paul hospitals of ART laboratory for diagnostic analysis during the data collection period were include by using convenient sampling technique with qualitative and quantitative data collection approach from May 1 to Jun 30, 2018.

\section{Data collection tools and procedure}

Data was collected by using self administered structured questionnaires for laboratory personnel and checklists for specimen collection adapted from previous similar literatures and record the pre-analytical error. All type of pre-analytical errors were documented by the investigators by using data collection sheet prepare for this purpose, by observing the phlebotomists actual performance.

\section{Data processing and analysis}

All data were entered and analyzed using SPSS software SPSS (Statistical Package for the Social Science) version 21 for Microsoft Windows. Before analysis data was cleaned and edited and observed carefully from Tikur Anbessa specialized hospital and St.Paul Millennium medical college in Addis Ababa city. The sums of errors were summarized. Their relative frequencies compared to the total specimens were also calculated and presented as a percentage, number and data was presented as tables and figures. 
Table 1: Socio-demographic characteristics of laboratory personnel at Tikur Anbessa specialized hospital and St. Paul Millennium medical college, Addis Ababa, Ethiopia, 2018.

\begin{tabular}{|l|l|l|}
\hline Category & Frequency & Percent (\%) \\
\hline $\begin{array}{l}\text { Sex } \\
\text { Male }\end{array}$ & 19 & 45.2 \\
Female & 23 & 54.8 \\
\hline Marital status & & \\
Single & 23 & 54.8 \\
Married & 19 & 45.2 \\
\hline Education & & \\
Certificate & 1 & 2.4 \\
diploma & 9 & 21.4 \\
degree and above & 32 & 76.2 \\
\hline Work experience & & \\
$\leq 1$ year & 13 & 31 \\
\hline 2-5 years & 16 & 38.1 \\
\hline 6-9 years & 7 & 16.7 \\
$\geq 10$ years & 6 & 14.3 \\
\hline Monthly income & & \\
$\leq 1000$ & 1 & 2.4 \\
\hline $1001-2000$ & 9 & 21.4 \\
2001-3000 & 5 & 11.9 \\
$\geq 3001$ & 27 & 64.3 \\
\hline
\end{tabular}

Table 2: General knowledge of laboratory personnel at Tikur Anbessa specialized hospital and St.Paul Millennium medical college, Addis Ababa, Ethiopia, 2018.

\begin{tabular}{|c|c|c|}
\hline $\begin{array}{l}\text { Have you take phlebotomy } \\
\text { training }\end{array}$ & Frequency & Percent \\
\hline Yes & 22 & 52.4 \\
\hline No & 20 & 47.6 \\
\hline \multicolumn{3}{|l|}{$\begin{array}{l}\text { How do you check identity of } \\
\text { patient when collecting blood }\end{array}$} \\
\hline I ask the patients relatives & 7 & 16.7 \\
\hline I check patients hospital ID & 25 & 59.5 \\
\hline I call patients name & 10 & 23.8 \\
\hline \multicolumn{3}{|l|}{$\begin{array}{l}\text { Do you label the collection time on } \\
\text { test tube }\end{array}$} \\
\hline Yes & 35 & 83.3 \\
\hline No & 7 & 16.7 \\
\hline \multicolumn{3}{|l|}{$\begin{array}{l}\text { If yes how do you mark sampling } \\
\text { time on request and tube }\end{array}$} \\
\hline Both tube and request & 28 & 71.8 \\
\hline Test tube only & 9 & 23.1 \\
\hline Not always but sometimes & 2 & 5.1 \\
\hline \multicolumn{3}{|l|}{$\begin{array}{l}\text { If you see hematoma when } \\
\text { performing blood collection what } \\
\text { did you do }\end{array}$} \\
\hline I stop before first tube collection & 25 & 59.5 \\
\hline I stop any time during sampling & 15 & 35.7 \\
\hline I stop after the sampling finished & 2 & 4.8 \\
\hline $\begin{array}{l}\text { Do you know recommended } \\
\text { minimum volume to be filled in } \\
\text { tube }\end{array}$ & & \\
\hline
\end{tabular}

\section{Result}

\section{Socio-demographic characteristics}

A total of 42 laboratory personnel from Tikur Anbessa specialized hospital and St. Paul Millennium medical college of Addis Ababa were involved in the study. Out of the 42 laboratory personnel 19 (45.2\%) were males and $23(54.8 \%)$ were females. The median age was 28.79 and 19 (45.2\%) were married as the detail depicted at Table 1.

\section{Phlebotomists awareness about phlebotomy ser- vice}

During this study $52.4 \%$ (22 of 42 ) phlebotomists were take training about phlebotomy and $47.6 \%$ (20 of 42 ) were not take training. $59.5 \%$ ( 25 of 42 ) of them perform identification of patients by checking the patient's hospital ID card, whereas $16.7 \%$ (7 of 42) of them said identification of patient's by ask the patient's relatives. $83.3 \%$ ( 35 of 42 ) of them were labeled the collection time on test tube from those $59.5 \%$ ( 25 of 42 ) were labeled in both tube and request, $16.7 \%$ (7 of 42)

\begin{tabular}{|c|c|c|}
\hline yes & 40 & 95.2 \\
\hline no & 2 & 4.8 \\
\hline \multicolumn{3}{|l|}{$\begin{array}{l}\text { Do you have adequate knowledge } \\
\text { on phlebotomy }\end{array}$} \\
\hline yes & 37 & 88.1 \\
\hline no & 5 & 11.9 \\
\hline \multicolumn{3}{|l|}{$\begin{array}{l}\text { Do you have knowledge in proper } \\
\text { collection and handling of sample }\end{array}$} \\
\hline yes & 24 & 57.1 \\
\hline no & 16 & 38.1 \\
\hline \multicolumn{3}{|l|}{$\begin{array}{l}\text { Do you have knowledge on impact } \\
\text { of phlebotomy in quality lab result }\end{array}$} \\
\hline yes & 38 & 90.5 \\
\hline no & 1 & 2.4 \\
\hline missing & 3 & 7.1 \\
\hline \multicolumn{3}{|l|}{$\begin{array}{l}\text { How do you mix the test tube has } \\
\text { additive }\end{array}$} \\
\hline I always mix & 38 & 90.5 \\
\hline $\begin{array}{l}\text { I always mix except when I am } \\
\text { busy }\end{array}$ & 4 & 9.5 \\
\hline \multicolumn{3}{|l|}{$\begin{array}{l}\text { How store the test tube } \\
\text { immediately after sampling }\end{array}$} \\
\hline in test tube stand rack & 42 & 100 \\
\hline \multicolumn{3}{|l|}{$\begin{array}{l}\text { When do you transport } \\
\text { specimens }\end{array}$} \\
\hline immediately after withdraw & 4 & 9.5 \\
\hline $\begin{array}{l}\text { within a time according to nature } \\
\text { request }\end{array}$ & 36 & 85.7 \\
\hline after all patient withdraw & 2 & 4.8 \\
\hline \multicolumn{3}{|l|}{ How do you transport specimen } \\
\hline by holding with my hand & 2 & 4.8 \\
\hline by test tube stand rack & 40 & 95.2 \\
\hline
\end{tabular}


were always labeled only test tube and the rest $16.7 \%$ ( 7 of 42) of them were not labeled on test tube. Majority, 95.2\% (40 of 42) of them know the recommended volume to be filled in the tube and $88.1 \%$ ( 37 of 42 ) had basic understanding on impact of phlebotomy in quality of laboratory and patient life 90.5 (38 of 42). The detail information was illustrated in Table 2 and Table 3.

\section{Status of specimen in ART laboratory at Tikur An- bessa and St.Paul hospital}

In this study a total of 427 (hematology 114 , clinical chemistry 105, CD4 123 and viral load 85 samples were submitted to laboratory for analysis of which the rate of pre-analytical error were $9.6 \%$ (41 of 427). Among this 272 (hematology 69, clinical chemistry 64, CD4 71 and viral load 68) were from St. Paul and 155 (hematology 44, clinical chemistry 41, CD4 53 and 17 viral load) were from Tikuranbessa. The most frequent requested laboratory test was CD4 $28.8 \%$ followed by hematology $26.7 \%$ and clinical chemistry $24.6 \%$ as shown in the Figure 1.

Table 3: Specimen collection responsible personnel and the site of specimen collected in percentage from May 16 to June 2018 at Tikur Anbessa and St. Paul hospital Addis Ababa, Ethiopia.

\begin{tabular}{|l|l|l|}
\hline Responsible for collection & Frequency & Percent \\
\hline laboratory personnel & 155 & 36.3 \\
\hline no laboratory personnel & 272 & 63.7 \\
\hline $\begin{array}{l}\text { Site where the specimen } \\
\text { collected }\end{array}$ & & \\
\hline emergency & 19 & 4.4 \\
\hline outpatient service & 408 & 95.6 \\
\hline
\end{tabular}

Despite the hospital working hour is 24 hours, the major of specimen collection work shift was collected in day shift during the morning from the site of outpatient service and emergency department by laboratory personnel and non-laboratory personnel. Outpatient (95.6\%) was the most frequent site of specimen collection followed by emergency department (4.4\%).

\section{Factors affecting the pre-analytical errors}

From 427 sample 386 were accepted for analysis and 41 (9.6\%) were not accepted because of errors in pre-analytical phase of laboratory diagnosis. The most frequent reason for error was miss labeling followed by hemolyzed and clotted sample as shown in Figure 2.

Stratification of data by the type of requested laboratory service revealed that the proportions of pre-analytical error were the highest in the clinical chemistry department 3.3\% (14 of 427) followed by CD4 3.0\% (13 of 427), hematology department $2.1 \%$ (9 of 427) and lastly from viral load department $0.9 \%$ (4 of 427). Comparing magnitude of errors based on originated hospitals, St. Paul hospitals account the higher, $65.9 \%$ (27 of 41) as illustrated in Table 4.

Further evaluation was performed in order to scrutinize the contributing factors, among the $22 \%$ (9 of 41) of error associated with hematology department were because of labeling error $44.4 \%$ ( 4 of 9), clotted and sample without request $22.2 \%$ ( 2 of 9) of each. Of the total sample that were error occurred in clinical chemistry department, $42.9 \%$ (6 of 14 ) were because of hemolyzed, $21.4 \%$ ( 7 of 14 ) because of clotted and insufficient amount for each and the remaining 14.3\% ( 2 of 14 ) were because of labeling error, whereas er-

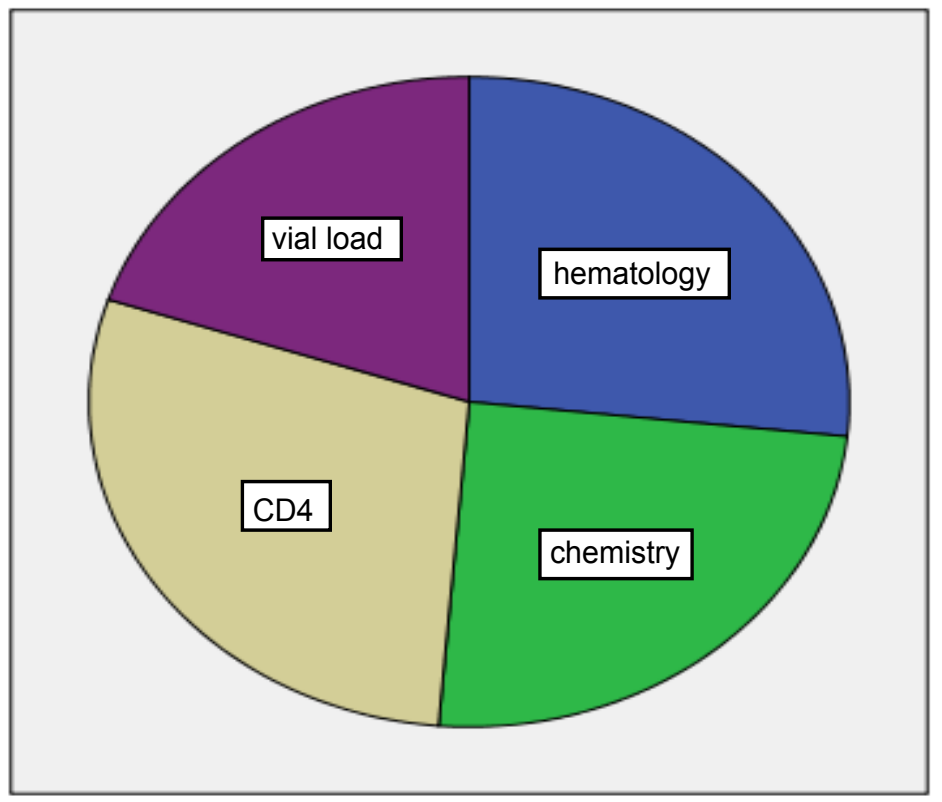

Figure 1: Sample distribution in each laboratory service department at Tikur Anbessa specialized hospital and St. Paul Millennium medical college, Addis Ababa, Ethiopia, 2018. 


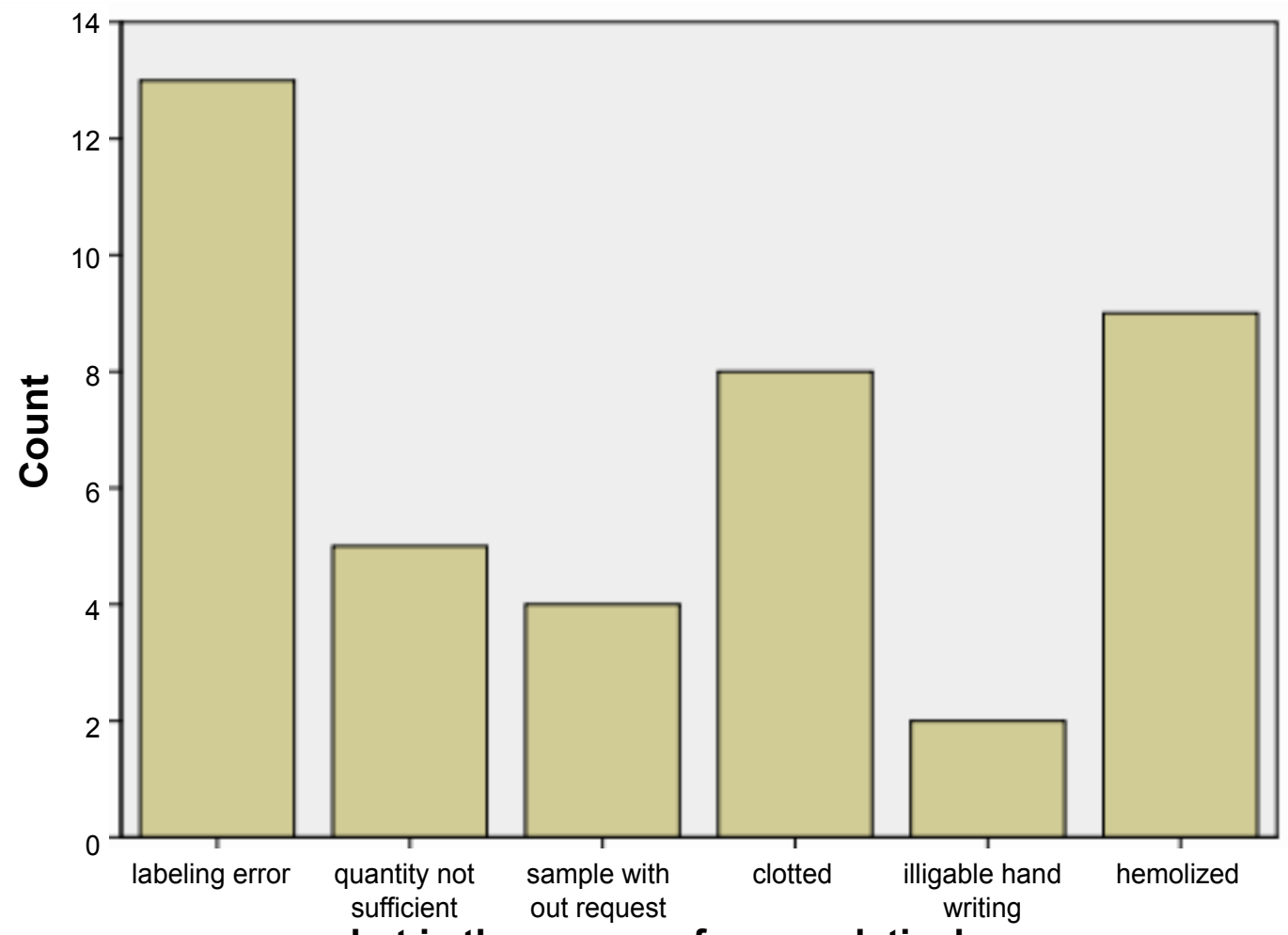

what is the reason of pre analytical error

Figure 2: The reason for pre-analytical error by percentage at Tikur Anbessa specialized hospital and St.Paul Millennium medical college, Addis Ababa, Ethiopia, 2018.

Table 4: Pre-analytical error at Tikur Anbessa specialized hospital and St. Paul Millennium medical college, Addis Ababa Ethiopia, 2018.

\begin{tabular}{|l|l|l|l|l|}
\hline & St. Paul & \multicolumn{2}{l|}{ Tikur Anbessa } \\
\hline Department & Frequency & Percent & Frequency & Percent \\
\hline Hematology & 6 & 22.2 & 3 & 21.4 \\
\hline Chemistry & 9 & 33.3 & 5 & 35.7 \\
\hline CD4 & 9 & 33.3 & 4 & 28.6 \\
\hline Viral load & 3 & 11.1 & 2 & 14.3 \\
\hline
\end{tabular}

Table 5: The reason of pre-analytical error by type of requested laboratory service Tikur Anbessa specialized hospital and St. Paul Millennium medical college, Addis Ababa Ethiopia, 2018.

\begin{tabular}{|l|l|l|l|l|l|}
\hline \multirow{2}{*}{ Reason of error } & \multicolumn{2}{l|}{ Requested laboratory service } & \multicolumn{2}{l|}{ Total } \\
\cline { 2 - 5 } & Hematology & Clinical chemistry & CD4 count & Viral load & \\
\hline Labeling error & $4(44.4 \%)$ & $2(14.3 \%)$ & $4(30.8 \%)$ & $3(60.0 \%)$ & $13(31.7 \%)$ \\
\hline Low quantity & 0 & $3(21.4 \%)$ & $2(15.4 \%)$ & 0 & $5(12.2 \%)$ \\
\hline Sample without request & $2(22.2 \%)$ & 0 & $1(7.7 \%)$ & $1(20.0 \%)$ & $4(9.8 \%)$ \\
\hline Clotted & $2(22.2 \%)$ & $3(21.4 \%)$ & $2(15.4 \%)$ & $1(20.0 \%)$ & $8(19.5 \%)$ \\
\hline Hemolyzed & $1(11.1)$ & $6(42.9 \%)$ & $2(15.4 \%)$ & 0 & $9(22.0 \%)$ \\
\hline Illegible hand writing & 0 & 0 & $2(15.4 \%)$ & 0 & $2(4.9 \%)$ \\
\hline Total & $9(100 \%)$ & $14(100 \%)$ & $13(100 \%)$ & $5(100 \%)$ & $41(100 \%)$ \\
\hline
\end{tabular}

ror happened in CD4 count department, 30.8\% (4 of 13) were because of labeling error followed by clotted sample, hemolyzed sample, insufficient amount and illegible hand writing $15.4 \%$ ( 2 of 13 ) for each and $7.7 \%$ (1of 13) were because of sample without request as the detail displayed at Table 5 .

\section{Discussion}

We conducted a cross-sectional study with the primary objective of determining the magnitude and factors affecting pre-analytical errors on ART laboratory at Tikur Anbessa specialized hospital and St. Paul Millennium medical college, Addis Ababa Ethiopia. 
Accordingly, $52.4 \%$ (22 of 42 ) professionals were take a competency based phlebotomy training and $47.6 \%$ ( 20 of 42 ) were did not have the specified training and did not follow the recommended procedure, which is discordant with WHO guide lines specifies that each laboratory should have their own standard operating procedure (SOP), which instructs the phlebotomists how to collect, handle, and manage phlebotomy service starting from patients identification up to providing of specimens for laboratory testing without affecting the quality of specimens. The difference may be due to status of the hospital, management system, recklessness of the lab personnel and workload [12].

According to CLSI H3-A5 and WHO guideline, blood collection materials should be labeled after confirming of patients and after insuring of enough blood collection for laboratory testing, collected tube should be labeled at least with patient's initials, identification number, date and time of collection, identification of the person collecting the specimen and address from where the test is requested. The specimen by itself should be identifiable without the need of requests [13]. However, in our study $59.5 \%$ (25 of 42) were perform identification of patients by checking only the patient's hospital ID card, $23.8 \%$ (10 of 42) of them by cross checking of patients with request paper and $16.7 \%$ (7 of 42 ) of them identification of patient's by ask the patient's relatives. $83.3 \%$ (35 of 42) of them were labeled the collection time on test tube from those $59.5 \%$ (25 of 42 ) were labeled in both tube and request, $16.7 \%$ (7 of 42 ) were always labeled only test tube and the rest $16.7 \%$ (7 of 42 ) of them were not labeled on test tube.

Plebani and Carraro investigated that pre-analytical errors accounted for $61.9 \%$ of laboratory errors detected (99/160), with the majority of errors occurring during specimen collection, which is correlates finding with our study [15].

Studies have documented most of the errors in the clinical laboratory occur in the pre-analytical phase. In 2001 study by Wiwanitkit found a pre-analytical error frequency of $0.11 \%$ (1048/935, 896 specimens). This was based on data collected prospectively over a 6-month period at the 2900-bed University-Hospital of Chulalongkorn (Thailand). However in our study the error magnitude is $9.6 \%$, the reason for this deviation not is that, may be due to level of quality laboratory equipment's or laboratory professional, developmental status of the hospitals nature: Our study sites were tertiary teaching with relatively demonstrated laboratory quality management system [16]. Similar study conducted in Salvagno, et al. and Ricos, et al. and which is six times greater to our study reported $55 \%$ pre-analytical errors, $33.9 \%$ of which were specimen collection errors. Despite the variety of reported pre-analytical errors in any given study, different in- vestigations tend to identify the same set of errors as occurring the most frequently. These most common errors were: Patient identification errors, insufficient specimen volume, specimens collected in the wrong type of tube, and poor sample quality (i.e. hemolyzed sample, clotted sample, contaminated sample) $[20,21]$, which is similar to our findings.

According to the current study, from 427 samples 386 were accepted for analysis and 41 were not accepted because of errors in pre-analytical phase of laboratory diagnosis. The most frequent reason for error was labeling error followed by hemolyzed and clotted sample. According to Proctor reported that specimen mislabeling was the most rampant pre-analytical error at Sunnybrook, accounting for $35 \%$ of pre-analytical errors over a 24-month period [22]. Therefore, current study has similarities on the most frequent pre-analytical error with the Proctor finding.

Dunn and Moga reported that $73 \%$ of patient misidentification events occurred in the pre-analytical phase of the laboratory and that $88 \%$ of pre-analytical events were associated with misidentification of patients [23], which is comparable to our study that $31.7 \%$ of pre-analytical errors were labeling error.

In our findings, despite the hospital working hour is 24 hours, the major of specimen collection work shift; all of the samples were collected in day shift from the site of outpatient service and emergency department by laboratory personnel and non-laboratory personnel. Arikan, et al. conducted a study of pre-analytical error frequency at the 1200-bed Ibn-iSina Hospital in Turkey with a one-month longitudinal prospective study and involved observations of 8393 day-time specimens and 4678-night shift/weekend specimens submitted for biochemical analysis. Thuslbn-iSina Hospital in Turkey works at day and night shifts which are different with our findings; it may be due to the shifts willing of patients to give sample, sufficient laboratory person availability time, and life style of the country [11].

\section{Conclusion and Recommendations}

Our finding shows the overall pre-analytical study rate was $9.6 \%$ and the most frequent reason for error was labeling error followed by hemolyzed and clotted sample. Our main take-home message is the need to prepare and adopt standard operating procedures for every laboratory activity which is done before sample gets the analytical stage.

The current study also shows on awareness of laboratory personnel about phlebotomy service that all laboratory personnel were not getting related competency-based training and even those who had training did not well practicing phlebotomy effectively. Therefore, we recommend that all laboratory personnel should get phlebotomy training which should designed and provided especial and organized specimen collection training 
for phlebotomists following WHO, CLSI guidelines and manufacturer's instructions.

Our findings also show that whatever the hospital working hour is 24 hours, the majority of specimen collection were in the day shift from the site of outpatient service and emergency department by laboratory personnel and non-laboratory personnel, which is a prone for errors. Hence, we suggest that the laboratory should have to work at both shifts to reduce work load because when there is a load of work there is high chance for the occurrence of error.

\section{Limitation of the Study}

Interviewed results were dependent on laboratory personnel response. So, biased information might be given as data were collected during their daily working time. However, the observational data helps to minimize this bias.

\section{Declarations}

\section{Ethics approval and consent to participate}

Ethical clearance to conduct the study was obtained from departmental research and ethics review committee (DRERC) of department of medical laboratory sciences, college of health science, Addis Ababa University, St. Paul's Hospital Millennium Medical college ethical committee and Tikur Anbesa specialzed teaching hospital ethical committee. A formal letter of cooperation was obtained from department of medical laboratory sciences, college of health science, Addis Ababa University to Tikuranbesa specialized hospital and St Paul's hospitals laboratories and they were informed.

\section{Consent for publication}

Participants were informed that all data collected would remain anonymous. That data would be treated statistically only and remain confidential.

\section{Availability of data and material}

All data generated or analyzed during this study are included in this manuscript.

\section{Competing interest}

All authors state that there are no competing interests.

\section{Funding}

There is no funding for this research.

\section{Authors' contributions}

All authors participate in conceived and designed the study, performing data collection, analyzed the data and drafted the manuscript and also all authors read and approved the final manuscript.

\section{Acknowledgments}

We would like to thank all laboratory personnel at Tikur Anbessa specialized hospital and St.Pual Millennium medical college hospital for contribution in success of this work and our thanks also extends to those all who cooperated with us in doing this work.

\section{References}

1. Agarwal R, Chaturvedi S, Chhillar N, Goyal R, Pant I, et al. (2012) Role of intervention on laboratory performance: Evaluation of quality indicators in a tertiary care hospital. Indian J Clin Biochem 27: 61-68.

2. Narayanan $S(2000)$ The pre analytic phase. An important component of laboratory medicine. Am J Cline Pathol 113: 429-452.

3. Lippi G, Guidi GC, Martiuzzi C, Plebani M (2006) Pre-analytical variability: The dark side of the moon in laboratory testing. Clin Chem Lab Med 44: 358-365.

4. Laposata M, Dighe A (2007) "Pre-pre" and "post-post" analytical error: High-incidence patient safety hazards involving the clinical laboratory. Clin Chem Lab Med 45: 712-719.

5. Lopis A, Alvarez V, Martínez-Brú C, Gómez R, Barba N, et al. (2011) Quality assurance in the pre-analytical phase. Applications and Experiences of Quality Control, 185-204.

6. Cohen S, Ramphai RR (2014) The need for a quality standard for assurance in medical research laboratories. Afr Journal of Hospitality Tourism and Leisure 3.

7. Bonini P, Plebani M, Ceriotti F, Rubboli F (2002) Errors in laboratory medicine. Clin Chem 48: 691-698.

8. Goldschmidt HMJ, Lent RW (1995) Gross errors and work flow analysis in the clinical laboratory. Klin Biochem Metab 3: 131-140.

9. Ambruster DA, Overcash DR, Reyes J (2014) Clinical chemistry laboratory automation in the $21^{\text {st }}$ Century - Amat Victoria curam (Victory loves careful preparation). Clin Biochem Rev 35: 143-153.

10. Makitalo O, Liikanen E (2013) Improving quality at the preanalytical phase of bloodsampling: Literature Review. International Journal of Biomedical Laboratory Science (IJBLS) 1: 7-16.

11. Arikan OA, Elmali E, Karaeren Z (2006) Evaluation of preanalytic errors in clinical laboratory practice. Lab Med 37: 478-480.

12. WHO. Guidelines on Drawing Blood: Best Practices in Phlebotomy. 2010. Geneva, Switzerland.

13. Clinical and Laboratory Standards Institute (CLSI) (2008) Collection, transport, and processing of blood specimens for testing plasma-based coagulation assays and molecular homeostasis assays. In: Wayne, PA ( $5^{\text {th }}$ edn) CLSI H21 -A5.

14. Lippi G, Guidi GC, Mattiuzzi C, Plebani M (2006) Pre-analytical variability: The dark side of the moon in laboratory testing. J Lab Med 30: 129-136.

15. Carraro P, Plebani M (2007) Errors in a stat laboratory: Types and frequencies 10 years later. Clin Chem 53: 13381342.

16. Wiwanitkit $V$ (2001) Types and frequency of preanalytical mistakes in the first Thai ISO 9002:1994 certified clinical laboratory a 6-month monitoring. BMC Clin Pathol 1.

17. Wondimeneh L, Aster T, Eshetu L, Abay S (2016) Evaluation of phlebotomy services in clinical laboratory setting in Addis Ababa public hospitals, Addis Ababa, Ethiopia. American Journal of Laboratory Medicine 1: 9-15. 
18. www.aau.edu.et/chs/tikurAnbesa specialized hospital/back ground of TikurAnbesa hospital/

19. Habtamu M, Aster T, Fatuma H (2015) Frequency of Specimen Rejection and associated factors at St. Paul Hospital Millennium Medical College, Addis Ababa Ethiopia. Journa of Multidisciplinary Research in Healthcare 2: 1-16.

20. Salvagno GL, Lippi GL, Bassi A, Poli G, Guidi GC (2004) Prevalence and type of pre-analytical problems for inpatients samples in coagulation laboratory. J Eval Clin Pract 14: 351-353.
21. Ricos C, Garcia-Victoria M, de la Fuente B (2004) Quality indicators and specifications for the extra-analytical phases in clinical laboratory management. Clin Chem Lab Med 42: 578-582.

22. Dzik WH, Murphy MF, Andreu G, Heddle N, Hogman C, et al. (2003) An international study of the performance of sample collection from patients. Vox Sang 85: 40-47.

23. Dunn EJ, Moga PJ (2010) Patient misidentification in laboratory medicine: a qualitative analysis of 227 root cause analysis reports in the veteran's health administration. Arch Pathol Lab Med 134: 244-255. 